\title{
Stress Dependence of the Switching Field in Glass Coated Microwires
}

\author{
E. Komová
}

Fac. of Aeronautics, TU, Rampova 7, 04121 Košice, Slovakia

M. Varga, R. VArga, P. VojtaníK

Inst. Phys., Fac. Sci., UPJS, Park Angelinum 9, 04154 Košice, Slovakia

J. Torrejon, M. Provencio and M. VÁzquez

ICMM CSIC, Cantoblaco, 28049 Madrid, Spain

Here we present the study of the stress dependence of the switching field in amorphous glass-coated magnetic microwire of composition FeNiMoB. Samples were heat treated in the temperature range from $250^{\circ} \mathrm{C}$ up to $500^{\circ} \mathrm{C}$ in order to obtain relaxed and nanocrystalline state. As-cast microwire shows strong stress dependence of the switching field, which decreases with the temperature of annealing. The sample is almost not stress dependent after heat treatment at $425^{\circ} \mathrm{C}$, because the magnetostriction vanishes. However, the strongest stress dependence was found for the microwire annealed at $400^{\circ} \mathrm{C}$, just below the optimal annealing temperature to obtain the nanocrystalline state.

PACS numbers: 75.50.Kj, 75.60.Ej

\section{Introduction}

The amorphous glass-coated microwires attract huge interest in last few years because of their extended ability for application $[1,2]$. On the other hand, the amorphous alloy of the composition FeNiMoB becomes a new class of soft magnetic materials as a precursor for the nanocrystalline materials [3, 4]. In order to combine perfect soft magnetic properties of new nanocrystalline alloys with the useful symmetry of microwires, we prepared the amorphous glass-coated microwire of the composition of FeNiMoB to obtain a new material suitable for application.

\section{Experimental}

Our study has been performed on glass-coated microwires with nominal composition $\mathrm{Fe}_{40} \mathrm{Ni}_{38} \mathrm{Mo}_{4} \mathrm{~B}_{18}$ prepared by the Taylor-Ulitovsky method. The diameter 
of the metal core was $8 \mu \mathrm{m}$ and the total diameter $12 \mu \mathrm{m}$. Pieces of microwire $7 \mathrm{~cm}$ long were taken for measurements by induction method [5], using triangular wave form at the frequency $100 \mathrm{~Hz}$. The samples were submitted to different thermal treatment $\left(T_{\mathrm{a}}=250^{\circ} \mathrm{C}\right.$ up to $500^{\circ} \mathrm{C}$, duration 1 hour $)$ and measured after subsequent cooling to room temperature $\left(20^{\circ} \mathrm{C}\right)$. Stress dependences of the switching fields were estimated for tensile stresses up to $140 \mathrm{MPa}$. Stress, applied on the metallic nucleus was calculated according to [6]:

$$
\sigma_{\mathrm{m}}=k P /\left(k S_{\mathrm{m}}+S_{\mathrm{gl}}\right),
$$

where $k=E_{\mathrm{m}} / E_{\mathrm{gl}}, E_{i}$ are the Young modulus of metal $\left(E_{\mathrm{m}}\right)$ and glass $\left(E_{\mathrm{gl}}\right), S_{\mathrm{m}}$ and $S_{\mathrm{gl}}$ the cross-section of the metallic nucleus and glass, respectively, and $P$ is the applied mechanical load.

\section{Results and discussion}

Figure 1 shows the stress dependence of the switching field of amorphous glass-coated FeNiMoB microwires treated at different temperatures from 250 up to $500^{\circ} \mathrm{C}$. As-cast sample shows strong dependence of the switching field on the applied stress where the switching field monotonously increases with the applied stress $\sigma$. Similar dependences have already been found for glass-coated microwires $[7,8]$. It was shown that the switching in amorphous glass-coated microwires arises from the nucleation-propagation model and therefore, the switching field $H_{\mathrm{sw}}$ is proportional to the square root of the applied stress according to

$$
H_{\mathrm{sw}} \sim\left[A \lambda_{\mathrm{s}}\left(\sigma_{\mathrm{a}}+\sigma_{\mathrm{i}}\right)\right]^{1 / 2},
$$

where $A$ is the exchange energy, $\lambda_{\mathrm{s}}$ is magnetostriction and strong stresses arise either from the applied load $\left(\sigma_{\mathrm{a}}\right)$ or they are introduced by drawing and quenching (as well as ones arising from the different thermal expansion coefficient of the glass and metallic nucleus) during the fabrication of microwires $\left(\sigma_{\mathrm{i}}\right)$.

Annealing of the microwires at low temperatures causes the release of the internal stresses introduced during microwires production. This results in the decrease in the switching field as well as in the decrease in its stress dependence. Moreover, the magnetostriction of amorphous FeNiMoB alloys decreases by annealing, too [4]. The minimum value of the switching field $H_{\mathrm{sw}}$ was observed for the annealing temperature $T_{\mathrm{a}}=350^{\circ} \mathrm{C}$.

After annealing of the microwire at $T_{\mathrm{a}}=375^{\circ} \mathrm{C}$, the sample shows no stress dependence of the switching field, because the stresses are almost completely removed by the annealing.

After annealing at $T_{\mathrm{a}}=400^{\circ} \mathrm{C} / 1 \mathrm{~h}$, the crystalline $\gamma$-FeNi phase appears [3]. However, the crystallites are very small and the distance between them is more than the exchange length. They act as the pinning centers for the closure domain wall and the switching field increases a little bit. As a result of the stresses introduced by the pinning centers, the switching field shows the strong stress dependence. 


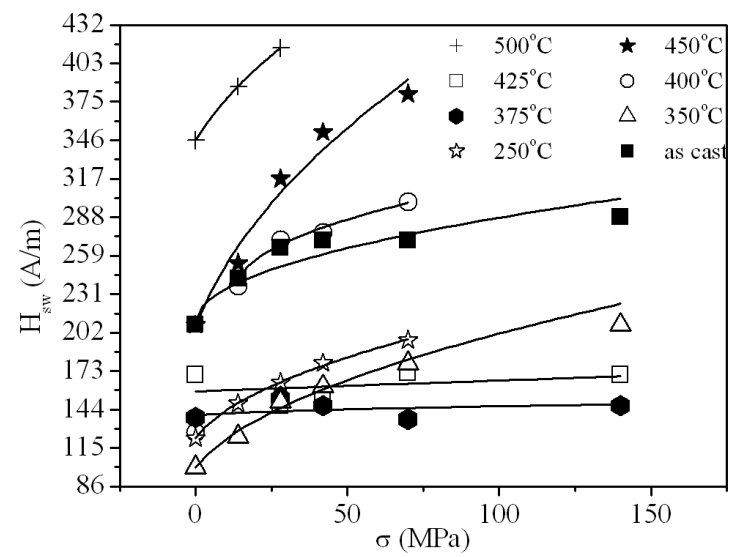

Fig. 1. Stress dependence of the switching field $H_{\mathrm{sw}}$ in amorphous glass-coated $\mathrm{Fe}_{40} \mathrm{Ni}_{38} \mathrm{Mo}_{4} \mathrm{~B}_{18}$ microwire after different thermal treatments. Full lines correspond to fit according to Eq. (2).

The annealing at $T_{\mathrm{a}}=425^{\circ} \mathrm{C}$ has been shown to be the optimum annealing temperature to obtain the nanocrystalline FeNiMoB alloy with the best soft magnetic properties (the lowest magnetostriction, the lowest coercive field, and the highest initial susceptibility) [4]. In the case of nanocrystalline FeNiMoB microwire, the switching field shows no stress dependence, probably as a result of very low magnetostriction. On the other hand, the switching field does not reach the minimum value. In the case of glass-coated microwire, one should take into account the stresses introduced by the glass coating (as a result of the different thermal expansion coefficient of the glass and metallic nucleus) during cooling after annealing.

The annealing at the temperature above the optimum annealing temperature $\left(T_{\mathrm{a}} \geq 450^{\circ} \mathrm{C}\right)$ leads to the strong stress dependence of the switching field in the nanocrystalline FeNiMoB microwire. The diameter of the grains increases and therefore the switching field increases, too. It is known that the coercivity of the nanocrystalline magnetic materials increases with the diameter of the crystalline grains $(D)$ following the $D^{6}$-law [9]. Moreover, after the treatment at $T_{\mathrm{a}}=500^{\circ} \mathrm{C} / 1 \mathrm{~h}$, the samples become brittle and the maximum applied stress can be no higher than $30 \mathrm{MPa}$.

\section{Conclusion}

We have studied the stress dependence of the switching field of amorphous and nanocrystalline bistable $\mathrm{Fe}_{40} \mathrm{Ni}_{38} \mathrm{Mo}_{4} \mathrm{~B}_{18}$ microwires. Depending on the thermal treatment, different stress dependences of the switching field have been measured. At low temperatures, the strong switching field dependence on the stress can be obtained, which is useful for stress sensing elements. Close to the optimal annealing temperature $\left(425^{\circ} \mathrm{C}\right)$, no stress dependence of the switching field was 
detected. Such behaviour is useful for the different sensing elements (temperature, current), which must not be stress sensitive.

In generally, the switching field is proportional to the square root of the applied stress, which corresponds to the nucleation-propagation model of the coercivity mechanism, which is valid in the case of amorphous and nanocrystalline microwires.

\section{Acknowledgments}

This work was supported by the scientific grants APVT-20-007804 and VEGA No. 1/3035/06.

\section{References}

[1] AMI601, G² Motion Sensor Datasheet, Aichi Micro Intelligent corp.

[2] M. Vazquez, Physica B 299, 302 (2001).

[3] R.V. Ramanujan, S.W. Du, J. Alloy Comp. 425, 251 (2006).

[4] P. Vojtanik, R. Matejko, R. Varga, V. Ocelik, Mater. Sci. Forum 373, 237 (2001).

[5] R. Varga, K.L. García, M. Vázquez, A. Zhukov, P. Vojtanik, Phys. Rev. B 70, $024402(2004)$.

[6] V. Zhukova, V.S. Larin, A.P. Zhukov, J. Appl. Phys. 94, 1115 (2003).

[7] P. Aragoneses, J.M. Blanco, L. Dominguez, J. Gonzalez, A. Zhukov, M. Vazquez, J. Phys. D 31, 3040 (1998).

[8] J. Gonzalez, N. Murillo, V. Larin, J.M. Barandiaran, M. Vazquez, A. Hernando, Sensors Actuators A 59, 100 (1997)

[9] G. Herzer, IEEE Trans. Magn. 26, 1397 (1990). 